\title{
A ecologia política de Enrique Dussel: aproximações para as lutas sociais na América Latina
}

The political ecology of Enrique Dussel: approaches for social struggles in Latin America

\author{
César Augusto Costa* \\ Carlos Frederico Loureiro**
}

\begin{abstract}
Resumo - Nesse texto abordamos a filosofia de Enrique Dussel, visando a aproximações teóricas entre a ecologia política e as lutas sociais na América Latina. O pensador discute a questão ambiental partindo da degradação instaurada pelo modo de produção capitalista e relações instituídas pelo sistema-mundo moderno colonial. Dussel, assim, fornece elementos para compreendermos os processos de expropriação capitalista e dominação eurocêntrica, que culminam na exploração dos povos e dimensionam a dinâmica das lutas sociais. Nessa linha de argumentação, após breve introdução ao tema, versamos sobre a categoria "encobrimento do Outro" como critério para o reconhecimento dos povos na dinâmica das lutas ambientais latinoamericanas. Em seguida, abordamos a ecologia política e as lutas sociais à luz do pensamento dusseliano. Por fim, pontuamos referenciais filosóficos e políticos do autor, que contribuem para refletir criticamente acerca das lutas sociais e da relação sociedade-natureza diante do padrão de acumulação capitalista na América Latina.

Palavras-chave: Enrique Dussel; modo de produção capitalista; eurocentrismo; lutas sociais; ecologia política.
\end{abstract}

\begin{abstract}
In this article, we approach the philosophy of Enrique Dussel, aiming at the theoretical approximations between political ecology and social struggles in Latin America. The thinker approaches the environmental issue from the degradation established by the capitalist mode of production and the relations instituted by the modern colonial world-system. Dussel thus provides elements for understanding the processes of capitalist expropriation and Eurocentric domination, culminating in the exploitation of peoples and dimensioning the dy-namics of social struggles. Following this line of
\end{abstract}

\footnotetext{
* Sociólogo. Pós-doutorado em Direito e Justiça Social/FURG. Professor/Pesquisador no Programa de Pós-Graduação em Política Social da Universidade Católica de Pelotas/UCPEL. Pesquisador do Laboratório de Investigações em Educação, Ambiente e Sociedade (LIEAS/UFRJ). Correspondência: Rua Rui Barbosa, bloco 651/ap. 104. CEP: 96030-420. Bairro Fragata, Pelotas/Rio Grande do Sul - Brasil. Email: <csc193@hotmail.com>.

** Doutor em Serviço Social/UFRJ. Professor/Pesquisador dos Programas de Pós-Graduação em Educação e Ecologia Social da Universidade Federal do Rio de Janeiro/UFRJ. Líder do Laboratório de Investigações em Educação, Ambiente e Sociedade (LIEAS/UFRJ). Correspondência: Universidade Federal do Rio de Janeiro, Faculdade de Educação. Av. Pasteur, 250 - fundos - Praia Vermelha. CEP: 22290-240 - Rio de Janeiro/RJ - Brasil. Email: <frederico89@gmail.com>.
} 
argument, after a brief introduction, we deal with the eclipse of "the Other" as a criterion for the recognition of peoples in the dynamics of Latin American environmental struggles. Next, we address political ecology and social struggles in light of Dusselian thought. Finally, we point out philosophical and political references of the author, which contribute to reflect critically on social struggles and the relationship between society and nature in the face of the pattern of capitalist accumulation in Latin America.

Keywords: Enrique Dussel; capitalist mode of production; Eurocentrism; social struggles; political ecology.

\section{Enrique Dussel: uma crítica ambiental para a América Latina}

O filósofo argentino Enrique Dussel é considerado pelos historiadores da América Latina (AL) como um pensador que contribuiu e construiu sólidas bases para a ética latino-americana da libertação (PINTO; RAPOSO, 2014). O pensador argentino notabilizou-se pela gênese e sistematização da filosofia da libertação, a partir da leitura crítica e subsunção das filosofias de Ricoeur, Levinas, Marx, entre outros, formulando uma filosofia política latino-americana (DUSSEL, 2007a) e, além disso, também da ética da libertação (DUSSEL, 2000). Ou seja, entendemos sua importância no panorama latino-americano da seguinte forma:

uno de los intelectuales más destacados de América Latina, por su capacidad de interpretar la realidad social y cultural de la segunda mitad del siglo XX y principios del XXI. Este trabajo describe el perfil de un intelectual del más alto nivel académico, surgido de la lucha político-ideológica de la década de 1960 en Argentina y México [...]. se sintetiza lo que constituye una teoría latinoamericana de la liberación a partir del ejercicio ético en el ámbito de las luchas políticas de los grupos marginales en América Latina y de aquellos sectores que participaron decididamente en estas luchas. (ARIAS, 2010, p. 183).

Partindo desta consideração inicial, indicamos que este autor problematiza a filosofia da América Latina. Esta, tendo caráter europeu, fez prevalecer a manutenção teórica e ideológica do colonizador sobre o colonizado. No entanto, Dussel, Zea e outros apontam que há uma filosofia latino-americana tencionada por uma filosofia que não se moldada apenas pelo pensamento eurocêntrico, mas que reivindica para si uma consciência crítica com método e epistemologia próprios (CAVALCANTE JR., 2012).

Através de sua filosofia da libertação, o autor analisa o processo opressivo da dominação colonial dos povos e culturas no plano mundial, questionando o discurso da modernidade. Sua filosofia e sua ética da liber- 


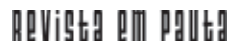

\} A ECOLOGIA POLÍTICA DE ENRIQUE DUSSEL - COSTA, C. A.; LOUREIRO, C. F. \}

DOI: $10.12957 /$ REP.2016.27859

tação fazem claramente uma opção política pelas vítimas do sistemamundo, compreendido como o processo de ampliação da influência cultural de um sistema civilizatório a outras culturas, e que tem no capitalismo sua expressão mais evidente (DUSSEL, 2000). Dussel pretende nos posicionar em um horizonte planetário global para além do eurocentrismo, o que impõe reconhecer a América Latina (a partir da periferia), visando interpelar a globalidade europeia. Sua ética da libertação é um "princípio material" (DUSSEL, 2007a) que parte do sujeito negado à luz do mundo periférico, cujo capitalismo, em seu processo de globalização-exclusão, foi determinado pelo sistema-mundo colonial eurocêntrico.

A incursão de Dussel ao pensamento marxista é fundamental para entender sua visão crítica no contexto periférico. Talvez a mais paradigmática de suas obras sobre Marx seja A produção teórica de Marx: um comentário aos Grundrisse (DUSSEL, 2012), no qual ele faz uma reconstrução analítica da obra do pensador alemão, com ênfase na "mais-valia" e no "trabalho excedente", assim como em suas derivações e consequências nos países da América Latina, na periferia do capitalismo mundial (ARIAS, 2010).

Dussel (2011) tem contribuído não somente com a discussão completa acerca dos manuscritos preparatórios de $O$ capital, mas também com uma reconstrução dos planos gerais do trabalho feito por Marx. Nesse movimento, o filósofo argentino incluiu na análise aguda do sociometabolismo do capital, oriunda do pensamento marxiano, reflexões provenientes do discurso libertário latino-americano. Sendo assim, "en las obras críticas sobre el discurso marxista, Dussel toma uma sana distancia para ejercer su acción analítica de todos y cada uno de los conceptos clave para entender el proceso de acumulación y explotación capitalistas en el marco del materialismo histórico" (ARIAS, 2010, p. 188). É sob as influências dessas categorias assinaladas que:

Dussel plantea que, la liberación, es una ética de la vida; la negación de la vida humana es el tema central, el punto de arranque decisivo de toda la crítica y la toma de conciencia de toda negatividad expresada en el sufrimiento de las víctimas, de los dominados, como el obrero, el indio, el esclavo africano o explotado asiático del mundo colonial; como la corporalidad femenina, la raza no-blanca, generaciones futuras que sufrirán en su corporalidad las consecuencias del deterioro ecológico; como viejos sin destino en la sociedad de consumo, niños de la calle, inmigrantes, refugiados, etcétera. (ARIAS, 2010, p. 195).

Além disso, ele soube se apropriar de categorias marxianas que auxiliaram na compreensão de como as relações sociais alienadas são determinantes na degradação ambiental, evitando discursos hipostasiados da moral ou da tecnologia como causas primárias da destruição, comuns no 


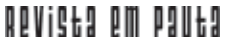

\} A ECOLOGIA POLITICA DE ENRIQUE DUSSEL - COSTA, C. A.; LOUREIRO, C. F. \}

DOI: $10.12957 /$ REP.2016.27859

campo ambiental. Em uma passagem magistral, Ao tratar da questão tecnológica, Dussel (2011, p. 235-236 - grifos no original) sintetiza:

De manera que la tecnología, tal como hoy la conocemos, no es sino una tecnología de las posibles y cuyo criterio de realidad o existencia queda determinado por ser la que mayor tasa de ganancia produjo a corto plazo (y debe ser a corto plazo, porque la 'competencia' no permite largos plazos, porque en esse lapso el capital en cuestión habría sido aniquilado por la dicha competencia por otros capitales (individuales, ramas o naciones) más desarrollados, o tecnológicamente mejor implementados en cuanto a producir por unidad productos con menor valor y proporcionalmente más plusvalor). Es decir, y esto es lo que se escapa a un cierto ecologismo ingenuo, la tecnología no es en sí un factor destructivo de la vida en la naturaleza (eticamente perversa por atentar contra la dignidad de la vida, que es en nuestro caso lo que interesa como lo más vulnerable de la naturaleza), sino que lo peligroso es el 'todo' que la usa y subsume para un fin antiecológico (eticamente perverso): el aumento cósico (y no humano ni ético) del plusvalor del capital. En este caso no es la tecnología la antiecológica sino el criterio cuya esencia es el capital: el capital constituye a la naturaleza, a la vida y a la persona del trabajador como mediaciones para la 'valorización del valor'. Ha invertido el principio de toda ética: ha colocado a la persona como medio, y a las cosas (el plusvalor) como fin (ya Kant lo había formulado explícita y correctamente). La causa creadora del plusvalor (el trabajo vivo) es ahora una mediación del aumento cósico del plusvalor (fundamento de la ganancia). La naturaleza, la vida, por su parte, es para el capital (y no para la humanidad) algo apropiable, explotable, pura mediación sin dignidad propia (componente esencial de la realidad sin valor 'de cambio', sin precio, diría Marx). Esta es la razón de la destrucción ecológica de la vida en la tierra, y lo peor es que el capital no tiene ninguna posibilidad de establecerse a sí mismo un límite (toda limitación es su total aniquilación como capital). Colocar al capital un límite ecológico es destruirlo en su esencia, es negar su propia 'lógica', que consiste en luchar mortalmente (homo homini lupus) en la 'competencia' por contrarrestar el tendencial descenso de la tasa de ganancia destruyendo todos los límites: the civilicing power of capital.

A argumentação central de sua filosofia considera o sofrimento do outro como a consequência do projeto civilizatório, no qual sujeitos subjugam outros (negros, pobres, índios, camponeses, trabalhadores, marginais) por meio de relações desiguais e opressivas de poder. Alguns estudos foram relevantes para ajudar o autor a fundamentar e criticar teoricamente, uma vez que ele partiu da miséria do povo para suscitar um pensamento filosófico tendo em vista essa realidade sofrida:

A descoberta da miséria do meu povo, percebida desde a minha infância no campo quase desértico, levou-me à Europa e à Israel. la, 
assim, descobrindo, como frisava o filósofo mexicano Leopoldo Zea, em sua obra América en la historia (1957), que a América Latina se encontra fora da história. Era preciso encontrar para ela um lugar na História Mundial, partindo da sua pobreza, e, assim, descobrir a sua realidade oculta. (DUSSEL, 1995, p. 14).

Dessa forma, a filosofia latino-americana pode ser vista assim:

É uma filosofia que brota do olhar do colonizado, daquele que historicamente foi oprimido e excluído. Organiza-se a partir do lado que foi negado. É uma filosofia que constrange o discurso da ordem, sendo, portanto, libertadora. Constitui-se, desta forma, como uma Filosofia da Libertação, a qual busca mostrar a possibilidade do diálogo mediante a afirmação da diferença e da alteridade numa perspectiva do diferente. Daquele que ficou a margem das construções ideológicas sociais. (CAVALCANTE JR., 2012, p. 3-4)

Assim, cabe perguntar: em termos de uma reflexão ambiental para a América Latina, quais pistas o pensador argentino poderia indicar? Entendemos que a questão social vem sendo pensada em contraposição à questão ambiental nos marcos do pensamento eurocêntrico e à luz do espectro econômico, social e político inerente ao capitalismo. Isto porque "é o consenso que se vê, hoje, em curso na América Latina onde as divergências entre esses campos políticos não se distinguem diante da questão ambiental (PORTO-GONÇALVES, 2015a, p. 2).

Na América Latina, desde finais dos anos 1990, precisamente após o ano de 2000, os movimentos sociais conseguiram pautar uma questão central para os governos progressistas na região: a desigualdade social. Desde então, os níveis de desigualdade social diminuíram visivelmente, conforme consta em vários relatórios da Comissão Econômica para a América Latina (Cepal). Segundo a Cepal (2012), as taxas de pobreza também declinaram de forma significativa, ancoradas, sobretudo, em políticas e programas sociais direcionados aos setores mais vulnerabilizados. Com a generalização da terceirização como principal forma de organização da produção e recrutamento de força de trabalho, grande parte dos postos de trabalho criados na última década possui baixa remuneração e elevada rotatividade. Vale destacar, ainda, que subsiste na América Latina um contingente considerável de trabalhadores em relações tradicionalmente precárias de trabalho. Segundo dados da Cepal (2012), em 2011, 7,1\% da população ocupada se dedicava ao trabalho doméstico; $21,7 \%$ não são trabalhadores assalariados, estando em profissões autônomas ou informais; apenas $61 \%$ da população ocupada tem acesso ao sistema de proteção à saúde; e, por fim, 60,2\% da população ocupada está protegida pelo sistema previdenciário.

Os indicadores de pobreza rural vêm diminuindo, mas se mantêm em patamares muito elevados na América Latina. De acordo com a Cepal (2012), em 2008, 34 milhões de pessoas estavam em condição de indigência 


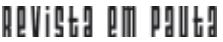

\} A ECOLOGIA POLITICA DE ENRIQUE DUSSEL - COSTA, C. A.; LOUREIRO, C. F. \}

DOI: $10.12957 /$ REP.2016.27859

no meio rural da região, embora em cada país haja bastante variação dos percentuais de pobreza em relação à população rural total. Grande parte das reduções de pobreza rural foram resultado da expansão de políticas e programas sociais, bem como incremento do gasto público. Os modelos de desenvolvimento econômico adotados na região latino-americana nos últimos anos não foram capazes, portanto, de afetar os elevados índices de pobreza rural, evidenciando, ao menos, a existência de uma profunda clivagem entre os setores agropecuários mais dinâmicos e os campesinatos empobrecidos.

Tendo isso em vista, mesmo países que não foram governados por forças que se dizem progressistas, como o Peru e a Colômbia, viram seus níveis de desigualdade social serem amenizados. Assim, o pensamento de Dussel nos propõe um enfrentamento concreto da realidade, buscando compreender que:

a população latino-americana é marcada pela pobreza, exclusão, marginalização e grande porcentagem de analfabetos. Uma profunda ideologia de submissão estava instaurada. Partindo destas condições, filósofos como Dussel, trilham pela construção de uma nova concepção filosófica, onde a libertação substituiria a exclusão e a dominação. (CAVALCANTE JR., 2012, p. 4).

Trata-se de uma filosofia que expõe a possibilidade do diálogo mediante a afirmação da diferença e da alteridade, numa perspectiva oposta à que ficou à margem das construções ideológicas e sociais próprias da feição metabólica que o capital assumiu na América Latina. Na crítica histórica de Porto-Gonçalves (2015a, p. 5), "como não podia deixar de ser, 1492 parece não ter fim. Os povos originários, seus parentes campesíndios/ camponeses e habitantes das periferias urbanas se tornem cada dia mais presentes no noticiário protagonizando r-existências". A naturalização das relações sociais capitalistas oculta o caráter das relações instituídas através de lutas e conflitos que nada têm de naturais, a não ser para as classes dominantes, que concebem sua dominação como obra da própria natureza. Para essas classes, as relações sociais instituídas, e que são as de dominação, são relações não só naturais, mas irracionais, desqualificando, assim, outros possíveis sujeitos históricos que não tiveram continuidade. Ou seja,

São íntimas as relações que estabelecem entre a concepção de que o homem deve dominar a natureza e a ideia de que o homem deve dominar outros homens (mulheres, crianças, adolescentes, velhos, negros, índios, homossexuais, operários, camponeses, etc.) - na medida em que estes últimos são socialmente vistos como seres da natureza. É preciso, pois desenvolver outro modo de pensar e agir que incorpore uma outra visão com a natureza-mulher; a naturezanegro; a natureza-índio; a natureza-criança; a natureza-adolescente; a natureza-velho; a natureza homossexual; a natureza-operário; a 
natureza-camponês, enfim, com a natureza-natureza; sobretudo, com a natureza-homem, que sabemos é independente-dependente do seu ecossistema. [...] Assim, trata-se de um outro projeto de sociedade; de um outro sentido para o viver; de uma cultura que subordine as técnicas aos seus fins e não fique subordinada a elas. Afinal, um modo de vida exige um outro modo de produzi-la. (PORTO-GONÇALVES, 2013, p. 134-135).

Acreditamos que a principal característica que pode ser revisitada no pensamento de Dussel é a centralidade do "princípio material" sobre a natureza, que pode ser alicerçado para refletir acerca da questão ambiental na América Latina (COSTA; LOUREIRO, 2015). O "princípio material" é visto desta forma:

A ética material da vida de Enrique Dussel coloca como tese central a defesa da vida. Isto significa desafiar o sistema capitalista que produz, reproduz e desenvolve a morte; morte para a maioria que não tem acesso aos bens materiais e aos bens simbólicos. A ação das classes dominantes internas da América Latina, em conjunto com as classes dominantes externas, determinou o ritmo da vida, do crescimento e do desenvolvimento dos países, estabelecendo, também, as diferentes relações entre as classes sociais envolvidas no processo econômico. (SILVA, 2012, p. 96-97).

Para o filósofo argentino, a ética da libertação, ancorada neste "princípio material", se converte numa ética em defesa da vida humana e, sobretudo, daqueles que vivem em permanente situação de exploração (BEORLEGUI, 2010). Ou seja, Dussel nos auxilia a compreender a dinâmica da questão ambiental no capitalismo a partir de uma lógica de "globalização-exclusão", indicando que:

Esse processo é exclusão das grandes maiorias da humanidade: as vítimas do sistema-mundo. Globalização-exclusão quer indicar o duplo movimento no qual se encontra presa a Periferia mundial: por um lado, a pretensa modernização dentro da globalização formal do capital (principalmente em seu nível financeiro - capital fictício, nos diz Marx); mas por outro lado, a exclusão material e o discurso formal crescente das vítimas desse pretenso processo civilizador. [...] A morte das maiorias exige uma ética da vida, e seus sofrimentos nos levam a pensar e a justificar a sua necessária libertação das cadeias que as prendem. (DUSSEL, 2000, p. 17 - grifos no original).

À luz desta compreensão ontológica, o pensador argentino postula que sua ética da libertação não pretende ser uma filosofia crítica para minorias nem para épocas de conflito ou revolução. É uma ética do cotidiano, em favor de e a partir das imensas maiorias da humanidade excluídas da globalização na atual "normalidade histórica vigente" (DUSSEL, 2000). Dussel (2007a), em seu pensamento, quer situar novos horizontes no que se 


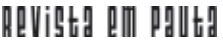

\} A ECOLOGIA POLITICA DE ENRIQUE DUSSEL - COSTA, C. A.; LOUREIRO, C. F. \}

DOI: $10.12957 /$ REP.2016.27859

refere à complexa articulação das massas vitimadas que emergem como comunidades, tendo militantes críticos como seus núcleos de referência. Para ele:

Trata-se dos novos movimentos sociais, políticos e econômicos, raciais, ecológicos, do 'gênero', étnicos, etc., que surgem no final deste século XX. Luta pelo reconhecimento de vítimas que operam transformações em diversas 'frentes de libertação', que esta Ética da Libertação fundamenta e legitima, podendo dar uma certa orientação, a partir dos critérios e princípios éticos, no dia-a-dia, para o exercício de libertação, desde as vítimas, de normas, ações, microestruturas, instituições ou sistemas de eticidade, sem ter de esperar o tempo das revoluções quando estas são 'impossíveis'. (DUSSEL, 2000, p. 13).

O desafio de compreender a questão ambiental, suas lutas e enfrentamentos sociais e políticos na América Latina parte do imperativo de uma libertação dos pobres e das vítimas do sistema mundo modernocolonial, que os confina a uma lógica de exclusão necessária neste sistema. Para o pensador argentino, tal situação se torna mais visível no meio do terror de uma lastimável miséria potencializada pelo capitalismo, que ainda aniquila a maioria da humanidade em pleno século XXI, junto com a irrefreável e destrutiva contaminação ecológica do planeta (DUSSEL, 2000). O geógrafo Porto-Gonçalves (2015a, p. 4-5) expõe de forma direta tais pressupostos:

vivemos o paradoxo de vermos o complexo de poder técnico/industrial-financeiro-latifundiário/mineiro-estatal do agronegócio e da mineração avançar sobre territórios em extensão (latifúndio) e profundidade (subsolo). O latifúndio, antes condenado por improdutivo, tornou-se produtivo e, parece, vai sendo assim consagrado, mostrando que a crítica ao latifúndio não era por concentrar poder, mas sim por não ser produtivo. Se é produtivo, que concentre poder, é o que se dá concretamente. O subsolo, nos anos 1950/60 estratégico para os projetos de afirmação da soberania nacional, hoje é objeto de concessões público-privadas onde reinventamos com expressões novas velhas práticas (encomendas, capitanias hereditárias, concessões aos 'amigos do rei'). Os códigos de mineração foram, em todos os países de nossa região, adequados ao novo 'consenso das commoditties' (Maristela Svampa), irmão-gêmeo do Consenso de Beijing (p. 4). [...]. Como as áreas sobre as quais avançam o latifúndio produtivo e a mineração não são vazios demográficos, o que está em curso é uma nova geopolítica da despossessão que atualiza o desenvolvimento do subdesenvolvimento que reprimariza e desintegra, conforme os dados da CEPAL que contrariam a retórica de crítica ao neoliberalismo, mas não ao capitalismo, e antiestadunidense, mas não anti-imperialista.

Desde o último quarto do século XX, as sociedades latino-americanas se converteram em laboratório global de políticas neoliberais. Com 


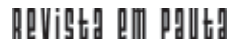

\} A ECOLOGIA POLÍTICA DE ENRIQUE DUSSEL - COSTA, C. A.; LOUREIRO, C. F. \}

DOI: $10.12957 /$ REP.2016.27859

o terrorismo de Estado dos anos 1970 inicia-se um novo ciclo de "acumulação por desposessão" (HARVEY, 2004), que culmina nas crises e na dívida dos anos 1980, bem como nas políticas do Consenso de Washington dos anos 1990, desembocando de forma abrupta no novo milênio, em plena instauração do atual ciclo de neodesenvolvimento extrativista.

Assim, o presente ensaio está organizado em três momentos. Inicialmente, versaremos sobre a categoria do "encobrimento do Outro" (DUSSEL, 1993) como critério determinante para o reconhecimento dos povos na dinâmica das lutas ambientais latino-americanas. Em seguida, buscaremos conciliar a perspectiva da ecologia política e das lutas sociais na América Latina à luz do filósofo argentino, partindo do reconhecimento de que agentes sociais com diferentes e desiguais níveis de poder e interesses opostos demandam disputas pela apropriação dos recursos naturais (PORTO-GONÇALVES, 2015a; 2015b).

Finalizando o ensaio, pontuaremos alguns referenciais filosóficos e políticos do pensamento de Enrique Dussel que contribuem de forma significativa para refletir criticamente acerca das lutas sociais, bem como da relação sociedade-natureza, o que faz considerarmos como um "princípio material" diante do padrão de acumulação capitalista na América Latina (LEHER, 2007; 2015).

\section{O encobrimento do "Outro" na dinâmica das lutas ambientais na América Latina}

Temos, como ponto de partida para refletir acerca da dinâmica interna das lutas ambientais na América Latina, a obra de Dussel (1993) intitulada 1492 - o encobrimento do Outro: a origem do mito da modernidade. Nesta obra, o filósofo argentino defende, como tese central, que o nascimento da modernidade aconteceu no ano de 1492, quando a Europa confrontou o seu "Outro", encontrando e o violando (VIEIRA, 2010). A tese dusseliana está inserida no bojo do contexto filosófico na América Latina, denominado filosofia da libertação, pois

seus estudos têm a marca de registrar a presença da filosofia latinoamericana de libertação no cenário da 'mundialização' da própria filosofia. Por isto, é tão importante um diálogo constante entre as diferentes posições filosóficas, tendo como fio orientador a questão do Outro. (VIEIRA, 2010, p. 121).

Assim, no entendimento de Arias (2010, p. 187):

Conviene destacar que el pensamiento dusseliano está abierto al debate con los 'otros', como filósofo de la región latinoamericana 


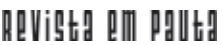

\} A ECOLOGIA POLITICA DE ENRIQUE DUSSEL - COSTA, C. A.; LOUREIRO, C. F. \}

DOI: $10.12957 /$ REP.2016.27859

adquiere no sólo conciencia paulatina de la originalidad de su discurso, sino también precisión y rigor, ya que este discurso tiene que contemporizar con la comunidad filosófica internacional en um sentido amplio, lo que le dará un reconocimiento universal a los espacios de reflexión filosófica de América Latina.

A crítica fundamental de Dussel ao Ocidente é seu caráter "fechado" em si mesmo. Ele pretende abrir o debate com outras concepções de mundo, também evitando a circularidade do pensamento latino-americano de forma semelhante ao que os europeus realizam. O pensador argentino pontua que é preciso compreender a história latino-americana para superar de forma radical a ocultação do seu ser, contribuindo para a libertação daqueles que negaram a própria América, isto é, os europeus (DUSSEL, 1993).

Rompendo com a concepção de que na "Descoberta" houve o "encontro de dois mundos", ele indica que o conceito de "encobrimento" é o que melhor define a dominação cultural-espiritual do europeu, impregnada na dominação econômica e militar. Para Vieira (2010, p. 123):

Abre-se aqui um espaço para um duplo movimento, de um lado, Dussel pretende ressaltar a crítica ao 'mito da modernidade'; de outro, a partir de exemplos históricos do momento da invasão, demonstrar a existência do pensamento abstrato no continente latino-americano, anterior mesmo à conquista.

A crítica de Dussel (1993), ancorado em Bartolomeu de Las Casas, parte da visão de que a modernidade só faria sentido se não consistisse na destruição da alteridade do índio. Contudo, Dussel (1993) não fica apenas neste nível de crítica, mas avança em uma tese polêmica: para o pensador, a Europa só foi tomar consciência de si mesma a partir das conquistas do "Novo Mundo", uma vez que antes era periferia do mundo muçulmano. Logo, o ano de 1492 consolidou a centralidade europeia, fazendo das outras civilizações a sua periferia. No entendimento de Vieira (2010, p. 124-125):

Se de um lado é evidente que a partir de 1492 o processo colonizador teve como consequência a anulação da alteridade do homem colonizado, de outro, é preciso também deixar evidente que a resistência diante da invasão se deu imediatamente. Neste sentido, compreende-se o recurso que Dussel faz ao pensamento reflexivo abstrato no continente latino-americano: os índios, com a sua cosmovisão compreendiam (e por que não, transformavam) a realidade. Ora, é a partir desta cosmovisão que se inseriu a resistência, a qual não frutificou 'devido à disparidade do desenvolvimento interpretativo dos fatos e da tecnologia militar; ela foi destruída em nome da 'nova ordem mundial', encobridora do 'mito sacrifical'.

Dussel (1993) ressalta a necessidade de emancipação de todas as classes dominadas e de que o bloco social dos oprimidos adquira corpo 


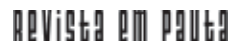

\} A ECOLOGIA POLÍTICA DE ENRIQUE DUSSEL - COSTA, C. A.; LOUREIRO, C. F. \}

DOI: $10.12957 /$ REP.2016.27859

próprio de sujeito histórico ao realizar uma verdadeira revolução política. São eles: os índios, as primeiras vítimas da modernidade; os negros, coisificados pela escravidão; os mestiços, novo habilitante da América e, deste modo, os únicos a completarem o seu milênio; os "crioullos", filhos e filhas europeus; os camponeses, que labutam a terra, boa parte sem a possuir; os operários, fração mais explorada do capitalismo mundial; e os marginais, exército nacional de trabalhadores que o capital periférico não pode subsumir.

De forma geral, devemos atentar para o fato de que o estatuto epistêmico permite ao pensador ter como ponto de partida a história para entender o fenômeno social atual. Neste aspecto, Dussel (1993), repassando historicamente a colonização, permite-nos compreender como se dá a formação do povo latino-americano, a qual está marcada, desde o surgimento, pela opressão ontologicamente negadora do seu ser. Ter como referência básica a realidade que o cerca é necessário para compreender a significação do ser alienado, contribuindo no processo de libertação (VIEIRA, 2010). Para o filósofo de Mendoza, a proposição está na superação do "mito da Modernidade" e de sua dominação, denominado por ele de transmodernidade (DUSSEL, 1993).

É partindo desta ontologia que buscaremos compreender a dinâmica da questão ambiental para os povos da América Latina, para a qual o pensamento dusseliano traz relevantes contribuições no processo de lutas ambientais e expropriações. Na crítica de Porto-Gonçalves (2015, p. 6):

É preciso sair dessa armadilha que separa o social do natural. Não associemos o desenvolvimento ao ambiente, como um novo/velho senso comum vem afirmando. Afinal, ambiente - enviroment - é envolvimento e não des-envolvimento [...]. A matriz de conhecimento que temos é, também, parte do problema até porque saber é poder [...]. Há grupos classes sociais/etnias/povos/nacionalidades que detém acervos de conhecimentos que nos ajudam nessa transição.

Tal perspectiva moderna, eurocêntrica e de dominação é reiterada por Dussel (1993, p. 186) quando ele aponta que:

Esta dominação produz vítimas (de muitas variadas formas), violência que é interpretada como um ato inevitável, e com o sentido quaseritual de sacrifício; o herói civilizador investe suas próprias vítimas do caráter de ser holocaustos de um sacrifício salvador (do colonizado, escravo africano, da mulher, da destruição ecológica da terra, etc.

Para o filósofo, a superação estaria na correalização da solidariedade, chamada por ele de analética, do centro/periferia, mulherhomem, do negro, do escravizado por outro modelo civilizatório. Ou seja, é a real subsunção da modernidade pela "alteridade", no reconhecimento das vítimas que a modernidade excluiu. Superar a modernidade implica 


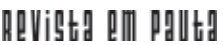

\} A ECOLOGIA POLÍTICA DE ENRIQUE DUSSEL - COSTA, C. A.; LOUREIRO, C. F. \}

DOI: $10.12957 /$ REP.2016.27859

trazer ao "descobrimento" o índio sacrificado, o negro escravizado, a mulher oprimida, a natureza dominada por relações econômicas, a criança e a cultura popular alienada, vítimas desta modernidade (DUSSEL, 1993).

\section{Enrique Dussel: uma ecologia política para a América Latina}

A ecologia política se refere ao estudo e reconhecimento de que agentes sociais com diferentes e desiguais níveis de poder e interesses opostos demandam, na produção das existências, recursos naturais num determinado contexto ecológico, disputando-os com outros agentes (LOUREIRO, 2012). É através deste movimento contraditório e conflituoso que as organizações sociais se estruturam, fazendo valer ou não seus interesses. Torna-se evidente que estamos refletindo acerca de tais postulados dentro do projeto societário capitalista.

Pensando estes elementos introdutórios, podemos questionar: qual a aproximação de Dussel à ecologia política? Que possibilidades e contribuições teóricas o pensador argentino pode oferecer? Qual a implicação na dinâmica das lutas ambientais? Ora, Dussel (1980), em sua clássica obra Filosofia da libertação na América Latina, indicava que é desde um mundo histórico, político, erótico ou simbolicamente determinado que compreendemos a natureza e interpretamos os entes naturais. Isto porque o europeu moderno compreendeu a nature ou Natur como sendo a matéria observável matematicamente (desde Galileu) ou explorável economicamente (desde a Revolução Industrial). A natureza, juntamente com o trabalho e o capital, é a origem do mítico progresso civilizador.

A partir disso é possível entender o que se quer indicar ao dizermos que a natureza é politicamente interpretada: ela é hermeneuticamente visualizada desde o centro ou da periferia, desde as diversas classes sociais e desde os sistemas políticos, principalmente, como matéria de um modo de produção numa formação social determinada. Levando estes elementos em consideração, Dussel certamente tem muito a contribuir neste debate que possui implicações para a América Latina!

No que se refere à importância do debate sobre a ecologia política, destacamos que ela possui origem na década de 1960 e tem como objetivo a compreensão de que agentes sociais, com opostos e desiguais níveis de poder e interesses diversos, demandam, na produção de suas existências, recursos naturais em um contexto ecológico (LOUREIRO; LAYRARGUES, 2013). Seu objetivo é gerar conhecimentos e compreensão acerca do próprio modo de funcionamento societário enquanto exigência para intervenções políticas; estas são superadoras ou reprodutoras das condições que engendram modos de produção e relações de propriedade dos bens criados ou naturais. Assim, 
O diferencial da ecologia política em relação à economia política, portanto, não está na aceitação da natureza como condição para a produção, pois isso é inerente a qualquer análise econômica, mas no modo como ela é qualificada. Na ecologia política a natureza é vista não somente como fonte de recursos, mas como ontologicamente prioritária para a existência humana, aquilo que nos antecede e que de nós independe, cuja dinâmica ecológica, mesmo que por nós mediada e transformada, precisa ser conhecida e respeitada a fim de que o modo de produção seja compatível com sua capacidade de suporte e de regeneraçã̃o. (LOUREIRO; LAYRARGUES, 2013, p. 56).

Isto não significa que com o fim hipotético do capitalismo os problemas ambientais estariam solucionados. Problemas são questões colocadas diante de certas condições, relações, apropriações e usos. Evidenciamos que tal condição deve ser enfrentada concretamente e não visualizada como fator descolado das relações complexas e materiais que a constituem. Este viés da ecologia política crítica é relevante para as ações ambientais, pois evita que se caia na armadilha do discurso abstrato; este coloca, no ser humano e nos comportamentos individuais, a responsabilidade planetária sem qualquer mediação social (LOUREIRO; LAYRARGUES, 2013).

Para a perspectiva crítica da ecologia política assumida neste artigo, existem pelo menos três elementos que evidenciam os porquês de os movimentos sociais não poderem ser vistos como secundários para este estudo (LOUREIRO; LAYRARGUES, 2013, p. 61). Assim: a) desqualificar as lutas dos movimentos sociais clássicos, que denunciam as mazelas do capitalismo, é um equívoco que despolitiza o debate e estabelece uma leitura não compatível com a dinâmica contraditória do real e, sobretudo, com as necessidades materiais das pessoas; $b$ ) as lutas dos movimentos sociais na América Latina se destacaram por terem enfrentado e exposto as incongruências do processo produtivo, tais como: agronegócio, indústria de celulose, mineração e reservas extrativistas. Estes aspectos deram materialidade ao debate ambiental e trouxeram para a arena política tais questões!; e c) o tema ecológico não é propriedade de nenhum agente social, nem mesmo dos que com ele buscam identificação. Portanto, é uma dimensão da prática política e fator de identidade entre sujeitos e grupos.

O não uso da categoria "ambiente", no Brasil, como estratégia de luta política dos movimentos sociais na década de 1990 possui duas explicações, segundo Loureiro (2012, p. 49-50):

O modo como o ambientalismo se consolidou durante os anos de 1970 e 1980 fez que ele assumisse muito do debate europeu. Além disso, por ser um pensamento de classe média e pertencendo à elite intelectual, veio com a desvantagem de não conseguir obter a adesão de grupos populares, uma vez que emerge ainda em um momento 


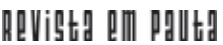

\} A ECOLOGIA POLITICA DE ENRIQUE DUSSEL - COSTA, C. A.; LOUREIRO, C. F. \}

DOI: $10.12957 /$ REP.2016.27859

do fim da ditadura militar e da redemocratização do país, e essa era a questão prioritária para os grupos de maior poder econômico. Com isso, um perfil majoritariamente fundado em abordagens estruturadas na cisão cultura-natureza ou em uma leitura idealizada da natureza impedia o diálogo com os movimentos sociais. O outro elemento se relaciona ao fato de que não só os movimentos sociais se rearticulam tardiamente (nos anos de 1980), como também as suas formas de organização se voltaram com muita ênfase (e não sem motivos) para o enfrentamento da ditadura. Assim, o foco se localizava na superação dos intensos mecanismos de dominação e no fortalecimento da democracia no país.

Atualmente, é necessário questionar se, nesta leitura, realmente existe algo de novo ou não nos denominados "novos movimentos sociais", incluindo o ambientalismo; além disso, se existem rupturas ou não com estes movimentos. Tais movimentos sociais, quando descolam a luta pela afirmação da diferença e da pluralidade das demais questões estruturais, provocam um esvaziamento político que favorece a ação pulverizada e prioriza a esfera do consumo e o indivíduo.

Compreendemos o surgimento dos movimentos sociais contemporâneos como ampliação do campo político e das suas práticas, em vez do seu abandono pelas causas culturais e ao contrário da concepção de novos "sujeitos históricos", que substituem os "velhos sujeitos" políticos renovados. No lugar de novas práticas sociais temos uma práxis social com dimensões ainda ignoradas. Mais que novos espaços políticos, o que temos são espaços políticos esquecidos no cotidiano e que precisam ser relacionados à totalidade material-concreta para que possam ser apreendidos. Não se trata de superar as lutas de classes, mas os novos movimentos sociais vêm complementar sob formas diversas e com distintos modos de vinculação, alguns mais ou menos diretos (MONTAÑO; DURIGUETO, 2011). Mesmo que ilustrem novidade, ao se analisar a dinâmica e a materialidade social, constata-se que estes movimentos reproduzem os pontos fundamentais do atual estágio do capitalismo. Esta afirmação indica que:

Concordamos com essa perspectiva quando os chamados novos movimentos sociais não perdem a dimensão de classe nas suas análises. Reconhecer que algo é determinante não significa estabelecer uma hierarquia entre o que é mais ou menos importante. Algo determinante é algo tendencialmente relevante ou algo sem o qual não se entende o conjunto das relações sociais em um contexto ou as causas de um fato. Logo, o determinante era e continua sendo o modo de produção capitalista, que estabelece como prioridade a acumulação de riquezas e não a satisfação de necessidades vitais. (LOUREIRO, 2012, p. 50-51).

Podemos apontar que, para Dussel (2007b), a questão ambiental deve ser refletida no horizonte da "periferia" que busca negar a dominação 


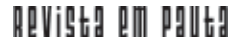

\} A ECOLOGIA POLÍTICA DE ENRIQUE DUSSEL - COSTA, C. A.; LOUREIRO, C. F. \}

DOI: $10.12957 /$ REP.2016.27859

e a exclusão no sistema-mundo colonial. Ou seja, "é um projeto de libertação da periferia negada desde a origem da modernidade" (DUSSEL, 2000, p. 65). A superação deste esquema de dominação implica a libertação do capitalismo (como modelo econômico), do eurocentrismo (enquanto ideologia), do machismo (na erótica), do predomínio da raça branca (no racismo), da destruição da natureza (na ecologia) e da libertação das vítimas oprimidas ou excluídas pela matriz moderno-colonial. É neste aspecto que a ética da libertação do filósofo argentino propõe que haja enfrentamento.

Para Dussel (2000, p. 65-66), a modernidade burguesa entende a natureza como um "objeto explorável", com vistas ao lucro capitalista, em termos econômicos. Além disso, possibilita a destruição da própria humanidade, por intermédio do capitalismo. O desenvolvimento do capitalismo começa a configurar-se na fase de desenvolvimento mercantil. Nesse período, o capital conseguiu mercantilizar os minerais, os vegetais, os animais e o espaço natural.

Assim, o pensador argentino entende que o sistema-mundo coIonial não tem condições de superar tais contradições. Ou seja, para Dussel (2007b), a ética da libertação reflete, a partir deste horizonte planetário, o sistema-mundo. Este duplo limite é o que configura a crise terminal deste processo civilizatório: a destruição ecológica da vida e a extinção da mesma na miséria e na fome da maioria da humanidade. Logo, Dussel (2000, p. 67) indica, de forma crítica, que:

A modernidade enfrenta a impossibilidade de subsumir as populações, as nações, as culturas que atacou agressivamente desde a sua origem, que excluiu de seu horizonte e que confina na miséria. É todo o tema da exclusão da alteridade da América Latina, da África e da Ásia, e de sua indomável vontade de sobrevivência (como reprodução e desenvolvimento da vida humana) [...]. Não gostaríamos de deixar de dizer que o 'sistema-mundo' globalizador chega a um limite enquanto simultaneamente exclui o Outro, que 'resiste' e de cuja afirmação parte o processo de negação da crítica da libertação.

A ecologia política se apropria da crítica capitalista, focalizando sua atenção nos modos pelos quais os agentes sociais nos processos econômicos, sociais e políticos disputam e compartilham os recursos naturais, bem como em qual contexto ecológico tais relações se estabelecem. $\mathrm{Na}$ concepção de Loureiro (2012, p. 30):

Na ecologia política não se fala na existência de populações sem considerar a territorialidade estabelecida. Ou seja, antes se pensava na atividade econômica de um grupo e sua viabilidade social. Agora, isso precisa ser situado em qual ecossistema, os limites disso, e em qual território. Exemplo: os extrativistas seringueiros só podem ser compreendidos por meio do trabalho que realizam em um tipo específico de floresta, numa relação direta com uma espécie que condi- 


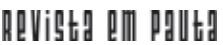

\} A ECOLOGIA POLITICA DE ENRIQUE DUSSEL - COSTA, C. A.; LOUREIRO, C. F. \}

DOI: $10.12957 /$ REP.2016.27859

ciona não só a economia gerada, mas a própria cultura e organização deste grupo. Modo de produção e modo de vida se definem dialeticamente, portanto.

Daí entendemos que acabam se tornando objeto de estudos os sujeitos da prática política ambientalista, as chamadas comunidades e populações tradicionais e grupos cujos modos de vida se definem em relação com a natureza. Por sua vez, esses grupos (quilombolas, pequenos agricultores, extrativistas, ribeirinhos, caiçaras etc.) se contrapõem a visões de mundo que mercantilizam a vida, dicotomizando a relação sociedade-natureza em sua feição metabólica (FOSTER, 2005). Para Araóz (2013, p. 15):

No se trata de un proceso nuevo en la historia económica (ecológica y política) de la región, sino todo lo contrario: estamos ante un fenómeno que, como advierte Alimonda (2011), puede ser considerado la marca de origen de lo latinoamericano, esto es, 'la persistente colonialidad' que afecta a su naturaleza [...]. La concepción colonial de la naturaleza, profundamente incrustada en la colonialidad del 'desarrollo', es una historia recurrente en América Latina. Somos hoy el producto de esa historia de 'cinco siglos igual'... Las gravosas desventajas geopolíticas, económico-estructurales, las específicamente ecológicas y las propiamente sociales y políticas en el ámbito interno, han sido profusamente investigadas.

Em termos de América Latina, ter uma reflexão que aproxime as lutas sociais e ambientais diante da relação sociometabólica no capitalismo nos parece desafiador; certamente, a perspectiva teórica de Dussel tem relevância nesse contexto, mesmo que ele não seja um pensador ambientalista. Ou seja, o foco da filosofia dusseliana está em consonância com os conflitos socioambientais provocados pelo padrão de acumulação do capital e pela nova geografia econômica mundial, que redefinem os termos do desenvolvimento desigual combinados ao capital (LEHER, 2015). Isso implica expor, de forma pontual, a articulação e a subordinação das frações burguesas locais com as frações hegemônicas. Além destas, também a força do núcleo dinâmico do capital, impulsionado pelo setor financeiro e pelas megacorporações que determinam preços e quantidade de mercadorias, calibrando a intensidade das exportações e da exploração do trabalho.

Assim, acelerou-se o ingresso de grandes corporações ligadas à exportação de matérias-primas; incrementaram-se as taxas de extração de hidrocarbonos, de minerais e de recursos florestais e pesqueiros; expandiram-se as superfícies de monocultivos de exportação; houve a radicalização de fases altamente contaminantes ou intensivas na água e energia e de processos de privatização-patenteamento da diversidade biológica por parte de grandes laboratórios. Outro aspecto importante deste processo foi o avanço em desenho de megaobras de infraestrutura e novos corredores transcontinentais para assegurar a conectividade dos territórios, a dispo- 


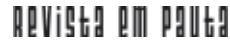

\} A ECOLOGIA POLÍTICA DE ENRIQUE DUSSEL - COSTA, C. A.; LOUREIRO, C. F. \}

DOI: $10.12957 /$ REP.2016.27859

nibilidade de água e energia aos investidores e a plena mobilidade dos recursos naturais.

Estas transformações implicaram uma abrupta expansão territorial das fronteiras do capital sobre a vasta riqueza e diversidade ecológica da região. Sob o crescente controle de grandes núcleos corporativos transnacionais, acabou se consolidando uma profunda reversão da economia latino-americana (ARAÓZ, 2013). A exportação de produtos primários passa a ser a chave da nova equação macroeconômica da região. A partir deste horizonte, Leher (2015, p. 25) entende que:

As conseqüências socioambientais são evidentes, pois esse verdadeiro saqueio de recursos naturais é indissociável das expropriações que, por sua vez, adensam os conflitos socioambientais no Brasil, América Latina, África e em grande parte da Ásia. Em outros termos: as frações burguesas locais, seus sócios majoritários e os governos que manejam o Estado (como se depreende o BNDES, do novo Código Florestal, do desmembramento do Ibama, etc.) aprofundam o capitalismo dependente, as expropriações e a exploração. Os conflitos socioambientais, portanto, estão no olho do furacão do capitalismo ultramoderno que coexiste com formas bárbaras e arcaicas de extração da mais-valia.

Dentro deste plano, a nova realidade da problemática ambiental pode ser vista em sua radicalidade com os sujeitos que empreendem lutas e resistências na região. Leher (2013, p. 229), ao refletir acerca do caráter contraposto à lógica sistêmica do capitalismo latino-americano, assevera que:

Os movimentos sociais antissistêmicos, críticos ao neodesenvolvimentismo, têm forjado experiências educativas auto-organizadas, como a educação do campo, a agroecologia e a Escola Nacional Florestan Fernandes (MST), nas comunidades quilombola, nas reservas extrativistas e nas periferias, em iniciativas culturais, como o hiphop, o funk, etc. Os povos indígenas (AbyaYala) da América Latina vêm difundindo um outro horizonte civilizatório, expresso no Bem Viver, radicalmente crítico ao neodesenvolvimento e ao capitalismo verde. Iniciativas internacionalistas como CLOC-Via Campesina forjam outros horizontes econômicos e sociais que recusam as expropriações e a exploração, bem como a colonialidade do saber. Nas lutas contra a mercantilização da natureza e de todas as esferas da vida, outra hegemonia vem sendo forjada [...]. Se a luta pela soberania alimentar requer o enfrentamento do agronegócio e a educação histórico-crítica e libertária exige o combate à mercantilização da educação, também a dignidade dos trabalhadores das fábricas, supermercados, centros de telemarketing, requer a negação de suas condições de fatores descartáveis da produção, processo que coisifica o trabalho e, por conseguinte, as mulheres e os homens.

As graves desvantagens geopolíticas e econômico-estruturais, especificamente ecológicas, bem como as propriamente sociais e políticas 


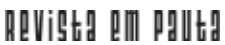

\} A ECOLOGIA POLITICA DE ENRIQUE DUSSEL - COSTA, C. A.; LOUREIRO, C. F. \}

DOI: $10.12957 /$ REP.2016.27859

no âmbito interno, têm sido investigadas e advertidas ao largo da própria história das Ciências Sociais na região. As relações entre extrativismo, oligarquias internas e regimes coloniais globais têm sido o "estopim" da tradição crítica do pensamento latino-americano. Para Dussel (2007a), um critério fundamental que se impõe na América Latina é a defesa dos recursos nacionais frente ao avanço dominador das transnacionais extrativas, produtivas e financeiras, que deixaram populações inteiras sem recursos futuros para reproduzir suas vidas. Segundo ele, o sistema vigente tem vítimas, as quais não-podem-viver plenamente. Sua vontade-de-viver é negada pelo projeto societário capitalista. Assim, Dussel entende ser necessária uma transformação deste "princípio material" (COSTA; LOUREIRO, 2015) da seguinte forma:

A mudança de atitude diante a natureza, que significa uma transformação no nível das instituições modernas, enfrenta algo muito mais radical que um mero projeto sócio-histórico diferente. Com efeito, a Modernidade - faz 500 anos (da invasão da América em 1492) - não foi somente o começo do capitalismo, do colonialismo, do eurocentrismo, mas o começo de um tipo de civilização. [...] É necessária uma revolução ecológica nunca antes sonhada, por nenhum outro pensador ainda nos séculos XIX e XX. (DUSSEL, 2007a, p. 139 - grifo no original).

Dussel (2007b) tece sua crítica refletindo acerca do "princípio material da natureza", que significa reconhecer o movimento de libertação histórica como um processo de luta no conflito de classes. Ou seja, indica que a realização da utopia possível se dá na medida em que é negada a alienação: "a negação da alienação, e a construção de outra sociedade humana, um novo tipo de sociedade", o "Reino da liberdade", que seja capaz e possível de libertar o homem (VIEIRA, 2010). A partir daí, Dussel (2007b) procura construir uma ética material da natureza, cujo objetivo é também resgatar a vida negada às vítimas dos sistemas de opressão.

Dussel (2007b) desenvolve, então, uma filosofia da libertação desde a América Latina, que enfrenta os enormes desafios do continente (exclusão, injustiça, analfabetismo). Nesse âmbito, seu pensamento alicerça uma responsabilidade ético-política para além do modelo hegemônico da totalidade europeia na América Latina, que perpassa a dimensão da natureza como princípio material.

Neste horizonte, as diversas críticas já realizadas por Dussel (1980; 2000; 2007a; 2007b), como também por outras elaborações teóricas de autores latino-americanos (PORTO-GONÇALVES, 2012; LEHER, 2007; 2013; 2015; LOUREIRO, 2012; 2013), evidenciam que não se trata do velho saque colonial, mas de um neoextrativismo (que inclui novos recursos, como a água, a biodiversidade/biotecnologias, o agronegócio) sob a gerência do capital financeiro. Este moveu seus centros de pensamento para 


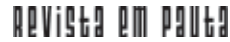

\} A ECOLOGIA POLÍTICA DE ENRIQUE DUSSEL - COSTA, C. A.; LOUREIRO, C. F. \}

DOI: $10.12957 /$ REP.2016.27859

produzir ideologias que justificam o extrativismo do século XXI, tais como a economia verde e seu respectivo desenvolvimento sustentável. No entanto, os efeitos macroestruturais, epistêmicos, ambientais, geopolíticos e geoeconômicos da "conquista e colonização" da América são conhecidos como o ponto de partida da ordem civilizatória do capital, fruto da organização do sistema-mundo moderno colonial (DUSSEL, 2000). Ou seja, tal organização impactou de forma perversa o padrão econômico do continente, pois:

En América Latina, la refundación neoliberal del orden colonial en estuvo trágicamente signada por la activación y desarrollo de un nuevo ciclo de violência imperialista. La cronología de este nuevo ciclo remite, en sus orígenes, a la violencia extrema de los terrorismos de Estado drásticamente impuestos durante los '70 y prolongada en la economía del terror de los '80, mediante la violencia disciplinadora-racionalizadora de la expropiación, iniciada con la deuda externa y los ajustes estructurales; prolongada y completada, luego, con la ola de privatizaciones, apertura comercial, desregulación financiera y flexibilización laboral de los noventa (p. 28-29) [...] Estamos en la fase del capitalismo senil, en el que todas las formas de la violencia colonial convergen y coexisten en un mismo escenario sociohistórico: el terror de la represión y la criminalización de las protestas; la violencia expropiatoria que expulsa a las poblaciones de sus territorios: la inversión que las despoja de sus fuentes de nutrientes, de agua, de aire y de energía. (ARAÓZ, 2013, p. 29 - grifos no original).

Sendo assim, o extrativismo latino-americano condensa e materializa este cenário neocolonial das grandes regiões, predominando variações da mesma lógica sacrificial: as zonas das colônias, onde a acumulação acontece mediante formas renovadas de escravidão, e zonas de colôniascommodities, uma vez que a expropriação política é exercida sobre os territórios. Logo, "en ambas, la eficacia práctica de la sujeción colonial extractivista puede verse a partir de una ecología política [...], enfocada a desenmascarar los regímenes de soportabilidad y epidermización de la sujeción colonial" (ARAÓZ, 2013, p. 32).

Para Dussel (1977), a relação prática com o outro inclui sempre uma relação de proximidade. Trata-se de descobrir a matéria potencial do trabalho humano e sua destruição e regeneração ecológica. Com efeito, a natureza como matéria explorável, destrutível, sem limite e rentável, causa ao aumento do capital, é um momento da ação dominadora do senhor (que obriga o escravo a trabalhar com essa natureza) e uma parte das interpretações óbvias do centro (primeiro a Europa, mas também os Estados Unidos). Essa troca de atitude homem-natureza culmina na Revolução Industrial e chega a alucinantes projeções no estado atual do capitalismo monopólico, sociedade de superconsumo e superprodução agressivo-destrutiva da ecologia natural (a prévia destruição do homem oprimido da periferia). Logo, para o pensador argentino: 


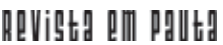

\} A ECOLOGIA POLITICA DE ENRIQUE DUSSEL - COSTA, C. A.; LOUREIRO, C. F. \}

DOI: $10.12957 /$ REP.2016.27859

Los conglomerados industriales transforman el jardín en basurero. Los desechos de las fábricas matan a los peces y los vegetales de los mares; enrarecen la atmósfera con gases asfixiantes; destruyen a los productores naturales de oxígeno (¡Estados Unidos roba a la periferia hasta su oxígeno, porque consume más del que produce!) [...] La naturaleza podría exterminar a esta especie que se ha tomado irracional por su sistema económico. La naturaleza, que pareciera permanecer pacientemente pasiva, responde con una lógica natural que no permite réplica: ¡El que me destruye se destruye! Pero el sistema tecnológicoeconómico de la formación social capitalista no pareciera inmutarse. Lanzado por su propio discurso al máximo de ganancia, y por ello de consumo-producción y viceversa, el imperialismo continúa su tarea devastadora. ¿Hasta cuándo? ¿Hasta qué límite? (DUSSEL, 1977, p. 138).

Apesar disso, os responsáveis políticos, econômicos e militares do sistema destruidor da natureza hoje, no mundo, são as potências desenvolvidas do centro, já que contaminam mais de $90 \%$ a Terra. Tal sistema capitalista e devastador do ambiente não propõe reduções em seu crescimento econômico porque este seria o seu fim, já que sua essência é pautada num crescimento irracional acelerado. Isso se torna evidente uma vez que Dussel (1977, p. 139) indica:

No será que una nueva actitud hombre-naturaleza es ya imposible para el capitalismo en la etapa del desarrollo en que se encuentra? ¿No será que modelos de relación hombre-naturaleza más pobres, menos destructores, menos consumidores, más económicos, más pacientes, más respetuosos de la naturaleza, sólo podrán surgir en pueblos que no han llegado al grado contradictorio de la tecnología dentro del capitalismo? ¿No será que la ruptura del sistema destructor se producirá cuando las relaciones hombre-hombres sean redefinidas? Pareciera que en el momento en que los pueblos periféricos exijan por sus materias primas (naturaleza trabajada por el siervo, el oprimido, el dominado), como ha sido algo ficticiamente fijado en el caso del petróleo, un precio justo, el de sus 'entes naturales' no manufacturados, en ese momento todo el sistema estallará. Claro que antes podrán aún exportar hacia la periferia sus industrias 'sucias' y asegurarse el control de las menos contaminantes y más complejas.

Consequentemente, para o filósofo argentino a libertação política da periferia parece ser então a condição essencial da possibilidade de regeneração do equilíbrio ecológico natural, em se tratando da libertação afirmada pela exterioridade cultural, e não somente uma imitação do processo econômico e tecnológico destrutivo do centro. Isto indicaria a autêntica humanização da natureza, a cultura na justiça (DUSSEL, 1977). 


\section{Reflexões dusselianas: uma ética da libertação para as lutas sociais}

Historicamente, cabe desvelar o processo de configuração do capitalismo no continente latino-americano, o que implica considerar a relação de dependência e de subordinação estabelecida entre a América Latina e os países centrais. "A condição periférica e dependente das economias latino-americanas garantiu a reprodução ampliada do capital nos países centrais e a perpetuação das condições de dominação econômica e política" (MONTAÑO; DURIGUETO, 2011, p. 249).

A nossa formação social vem sendo marcada pelo desafio da libertação, haja vista o caráter de subordinação ao sistema mundo-moderno colonial (1492) (DUSSEL, 2000), bem como nossa inserção ao capitalismo colonial e metabólico que foi alicerçado na América Latina. Tal caráter de subordinação/dependência propõe que nos desprendamos de leituras colonizadoras que foram forjadas e que vinculam a natureza inferior (social, política, cultural e econômica). Assim,

afirmamos, pois, que é da natureza do pensamento/ação colonial inferiorizar o diferente como condição da sua colonização: ninguém coloniza ninguém que considere igual ou eventualmente superior. Enfim, a inferiorização do outro/do diferente é condição da colonização. Logo, descolonizemos. (PORTO-GONÇALVES, 2015, p. 2).

Nesta ótica, não somos um "novo continente", como apregoaram os "invasores/colonizadores" ao falarem de "descobrimento da América", consagrando a data de fundação do "novo mundo" em 1492. Para Dussel (1993), estamos diante do "encobrimento do outro", que acabou, assim, invisibilizando etnias/povos/nacionalidades/civilizações nesse domínio geográfico forjado de forma violenta. De acordo com Zanotelli (2014, p. 496):

Este projeto será o programático e sistemático encobrimento e negação do outro: do índio, do negro, da mulher, da corporeidade, da sensorialidade, da afetividade, da sexualidade, num dualismo contraditório e insuperável bebido na fonte indo-europeia [...]. Em cada etapa, em cada época a colonização teve novas facetas, novas modalidades. Novas e cada vez mais profundas. Desde a invasão militar, a colonização econômica (que transformou o Brasil em latifúndios monocultores, exportadores e escravagistas), a colonização política em toda a sua estrutura e funcionamento, até a colonização cultural, ideológica, científica, técnica, artística e religiosa, em todas as dimensões. Depois da proclamação da independência da América Latina, nossos colonizadores interinos, endócrinos, foram os crioulos, os capatazes que substituíram a metrópole europeia. A colonização se tornou interna e internalizada.

No que tange às lutas sociais na América Latina e à leitura histórica e libertária, compreende-se que o continente experimentou sua primeira 


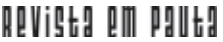

\} A ECOLOGIA POLITICA DE ENRIQUE DUSSEL - COSTA, C. A.; LOUREIRO, C. F. \}

DOI: $10.12957 /$ REP.2016.27859

revolução do século XX protagonizada pelos campesíndios/indigenatos em 1910, no México. Isto porque a Reforma Agrária entraria como questão política central para pensar a democracia e a justiça social.

Em torno da concentração da terra estruturam-se relações sociais e de poder das mais perversas do mundo, profundamente marcadas pelas desigualdades sociais. A injustiça social traz no bojo a discriminação étnicoracial, tornando inseparáveis, entre nós, a condição de raça e classe (PORTO-GONÇALVES, 2015). Araóz (2013) cunhou o termo "Princípio Potosi", definido como saqueio de recursos naturais e desterritorialização dos povos originários a serviço do padrão de acumulação do capital. Processo experienciado desde a década de 1970, a partir de um violento processo expropriatório, que pode ser evidenciado pela suburbanização que o mundo vivencia na América Latina. É nesta perspectiva que, para Dussel (2011, p. 228), "una Ética de la Liberación debe tratar decididamente un tema esencial: la cuestión ecológica; pero lo hará a su manera. Una vez más Marx vendrá em su ayuda. Tomemos este tema como un ejemplo del discurso de la Ética de la Liberación". Do mesmo modo, o filósofo argentino assim se posiciona:

Por lo general el tema ecológico ronda la destrucción de la vida en la tierra por una tecnología devastadora. Sin embargo, la esencial no es tanto la tecnología sino el criterio de subsunción de la dicha tecnología en el processo de producción del sistema capitalista en vigor. La tecnología es el efecto del uso de un criterio que es la causa de la extinción de la vida en el Planeta. (DUSSEL, 2011, p. 228).

No entendimento de Dussel (2011), Marx pode ajudar a situar a problemática dentro de uma visão mais concreta e crítica, o que permitiria um desenvolvimento inesperado da ética da libertação ecológica, recuperando a importância da corporalidade humana e, mais ainda, desvelando a ingenuidade de alguns ecologistas que, com toda sua boa vontade, "fazem ao jogo do capital". Desse modo, o autor argentino traz a célebre passagem de Marx (1875), publicada na Crítica ao programa de Gotha, que indica:

El trabajo no es la fuente de toda riqueza - comienza a explicar Marx. La naturaleza es la fuente de los valores de uso (ique son los que verdaderamente integran la riqueza material!), ni más ni menos que el trabajo, que no es más que la manifestación de una fuerza, de la fuerza de trabajo del hombre [...]. (MARX apud DUSSEL, 2011, p. 229).

Tal passagem nos ajuda a observar o seguinte: em primeiro lugar, que o trabalho não é a fonte de toda a riqueza, mas de algumas; em segundo, que a natureza é a fonte de todas as riquezas naturais, condições de toda a produção possível; em terceiro lugar, que o capitalismo tem distorcido a relação pessoa-natureza ao fazer da natureza uma possessão de alguns meios 


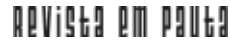

\} A ECOLOGIA POLÍTICA DE ENRIQUE DUSSEL - COSTA, C. A.; LOUREIRO, C. F. \}

DOI: $10.12957 /$ REP.2016.27859

e exclusão de outros, pervertendo uma relação adequada com ela; em quarto, que isto é possível porque uns dominam os outros (a relação social como força de coação política legítima) (DUSSEL, 2011).

Dessa maneira, podemos formular, a partir de Dussel (2011), que a estratégia argumentativa de Marx, assim como os movimentos sociais dos trabalhadores desde o século XVIII, destruíam as máquinas por entender que estas "roubavam" seus trabalhos. Do mesmo modo, também os ecologistas dos séculos XX e XXI, que ajuízam de forma negativa a tecnologia, crendo que ela é a causa da deterioração ecológica da Terra. Em ambos os casos eles se opuseram ao efeito, e não a causa. Sendo assim, o pensador argentino assevera que:

La causa no fue tocada ni atacada, siguió incuestionada e invisible su curso triunfal y destructor de la vida en la naturaleza y de los trabajadores, de la persona humana en el caso de la mayoría de la humanidad. La causa es el capital, con respecto al cual tanto la máquina en particular como la tecnología en general son determinaciones internas subsumidas según su criterio esencial: el aumento de la tasa de ganancia (que supone aumento de plusvalor, fundamentalmente) en el proceso de la competencia entre capitales [...] El Capital subsume al trabajo vivo, las condiciones de trabajo, etcétera, y las constituye como sus propias 'determinaciones'. La tecnología es un medio de trabajo, una condición de la producción, una mediación cuya finalidad es aumentar la productividad de la fuerza de trabajo para disminuir el valor del producto o para bajar el costo de la capacidad de trabajo; es decir, aumentar el plusvalor relativo (y su tasa). (DUSSEL, 2011, p. 232-234).

Tendo em vista este referencial dusseliano para redefinição da nossa relação sociedade-natureza, consideramos que o pensador argentino contribui para questionar o marco das relações subsumidas pelo capitalismo através do sistema-mundo moderno colonial (1492), que ainda hoje impera na América Latina em razão de suas lutas sociais. Fator que é reiterado por Porto-Gonçalves (2015, p. 6-7) ao pontuar que:

Basta observar a violência contra a Amazônia e seus povos, mas também sobre a Araucania/Patagônia, os Pampas e as savanas (no Brasil, os cerrados). Da r-existência com/contra esse processo surge a luta pela reapropriação social da natureza, como the chamaria Enrique Leff, um dos maiores expoentes de uma das principais contribuições de nosso continente às ciências sociais contemporâneas, qual seja, a Ecologia Política, campo que reúne geógrafos, sociólogos, antropólogos e cientistas políticos de nosso continente com uma agenda de investigação muito atenta e próxima às lutas desses grupos/ classes sociais/etnias/povos/nacionalidades [...]. Luta pela Vida, pela Dignidade e Território em que vários desses movimentos indicam que a vida não pode ser pensada fora da natureza, como na tradição científica hegemônica eurocêntrica. As Reservas Extrativistas dos 


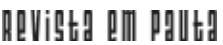

\} A ECOLOGIA POLITICA DE ENRIQUE DUSSEL - COSTA, C. A.; LOUREIRO, C. F. \}

DOI: $10.12957 /$ REP.2016.27859

seringueiros da Amazônia brasileira, emprestam ao conceito de extrativismo um sentido positivo, ao contrário do produtivismo desenvolvimentista que acreditar que tudo produz, como indica a tradição antropocêntrica e, assim, olvida que não produzimos água, minerais.

Para Dussel (2011), é a partir deste horizonte que a vida na Terra deve se orientar hoje, ou seja, o "objeto" de uma teoria ecológica que supõe uma comunidade de reprodução ética da vida e que permite uma crítica radical do capital, entendido como causa de extinção dos recursos naturais (meros meios de produção sem dignidade própria) e da maioria da humanidade (mera força de trabalho). Segundo Dussel (2011, p. 236),

Marx nos da así el marco teórico para desarrollar en tan urgente capítulo de la Teoría y Ética de la Liberación ecológica. Es decir, siendo el capital el fetiche que exige víctimas humanas en la historia presente, la tecnología se encuentra atrapada en una 'relación social' (de perversidad ética).

Considerando a retomada do pensamento de Marx pelo filósofo argentino, Porto-Gonçalves (2015b, p. 7) reforça de forma explícita a contribuição do pensamento latino-americano para as lutas sociais:

Enfim, há um enorme legado teórico-político que nos vem desde Guaman Poma de Ayala, Simon Rodrigues, Simon Bolivar, José Artigas, José Maria Caycedo, José Martí, Emiliano Zapata, José Carlos Mariategui, Franz Fanon, Aymé Cesaire, C. R. James, Pablo Gonzalez Casanova, Zavaleta Mercado, Florestan Fernandes, Silvia Rivera Cusicanqui, Rachel Gutierrez, Anibal Quijano, Maristela Svampa, Enrique Leff, Enrique Dussel, Walter Mignolo, Ramon Grosfogel, Catherine Walsh, Arturo Escobar, Rui Mauro Marini, Norma Giarraca, Raul Zibechi, Pablo Mamani, Alberto Acosta entre tantos e tantas que haveremos de considerar para um diálogo denso com o pensamento crítico do sistema mundo capitalista moderno colonial em sua heterogeneidade histórico-estrutural.

À luz do que foi explicitado neste texto, a contribuição de Dussel para refletir acerca da dinâmica das lutas sociais no panorama de uma ecologia política está no fato de que, para o argentino, "la liberación ecológica de la tecnología de la subsunción realizada por el capital, es una tarea de conciencia ética, económica y de organización política actual" (DUSSEL, 2011, p. 235). Do mesmo modo, a filosofia de Dussel transita por reflexões apoiadas nas categorias reconhecidas do marxismo, considerando que o princípio ecológico por excelência de toda ecologia política está centrado no valor da natureza, como vem sendo qualificado (LOUREIRO, 2012), e no seu "princípio material" (COSTA; LOUREIRO, 2015).

Apontamos que Dussel (2011), ancorado em Marx, sugere que o capital, ou seja, o processo de competência entre os capitais, é a verdadeira 


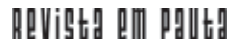

\} A ECOLOGIA POLÍTICA DE ENRIQUE DUSSEL - COSTA, C. A.; LOUREIRO, C. F. \}

DOI: $10.12957 /$ REP.2016.27859

causa destruidora da vida na natureza e dos trabalhadores, comunidades, povos originários, tradicionais e quilombolas, bem como ocasiona os demais impactos tensionados pela feição metabólica do capitalismo colonial. Isto porque coloca as "pessoas como meio" e as "coisas como fim". Partindo deste postulado, Zanotelli (2014, p. 499) compreende que:

Muito embora frágil e limitada, a possibilidade das descolonialidade dos saberes, das práticas e dos poderes é viável, é necessária, é urgente. As comunidades indígenas, quilombolas, dos que mais sofrem na carne os efeitos nefastos da colonialidade, clamam e vivem da possibilidade de sua superação. Eles ensinam, testemunham e exigem uma possibilidade humana para além das colonialidades.

Dussel entende que, nas culturas indígenas da América Latina existe uma afirmação da natureza mais integrada, ecológica, sociobiodiversa e mais necessária do que o modo como a modernidade capitalista a define, uma vez que este a reduz como algo explorável, vendível e destrutível (DUSSEL, 2003).

Frente a isso, a proposta política de Dussel (1986) caracteriza outro projeto societário constituído de novas relações, relações verdadeiramente humanas, de respeito à alteridade, de respeito à vida, já que o clamor dos excluídos, do "outro negado", exige verdade e justiça para que possamos ter identidade humana e possibilidade de ser. Isto é, significa opor-se ao processo atual que ignora o que é o capital e como ele funciona, entendimento determinante para o continente latino-americano realizar o enfrentamento político no limiar das lutas sociais e resistências diante do padrão de acumulação capitalista (LEHER, 2007; 2015).

Por fim, compreendemos que a aproximação entre Dussel e as lutas sociais pode ser evidenciada na proposta de superação do atual "mito da modernidade". Mito que, em termos ambientais, permanece alienando de forma violenta e eurocêntrica as condições sociais da periferia negada, do homem, da mulher e do indígena subalternizados, do negro escravizado, das comunidades tradicionais e dos demais grupos sociais excluídos, que buscam sua libertação pela superação deste modelo civilizatório (DUSSEL, 1993). 


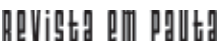

\} A ECOLOGIA POLÍTICA DE ENRIQUE DUSSEL - COSTA, C. A.; LOUREIRO, C. F. \}

DOI: 10.12957/REP.2016.27859

\section{Referências}

ARÁOZ, H. M. Orden neocolonial, extractivismo y ecología política de las emociones. RBSE - Revista Brasileira de Sociologia da Emoção, v. 12, n. 34, abr. 2013.

ARIAS, A. P. Enrique Dussel: una aproximación a su pensamiento. Veredas - Revista del pensamiento sociologico, México: UAM, 2010.

BEORLEGUI, C. Historia del pensamiento filosófico latinoamericano. Bilbao: Universidad de Deusto, 2010.

CAVALCANTE JR., J. A perspectiva filosófica de Enrique Dussel. Revista Sophia, n. 12, 2012.

CEPAL. Comissão Econômica para América Latina e Caribe. Panorama Social da América Latina, 2012. Disponível em: <http://www.cepal.org/publica ciones/xml/5/48455/PanoramaSocial2012.pdf. >. Acesso: em 1 fev. 2016.

COSTA, C. A.; LOUREIRO, C. F. A natureza como "princípio material" de libertação: referenciais para a questão ambiental a partir de Enrique Dussel. Educação temática digital, Campinas, v. 17, n. 2, 2015.

DUSSEL, E. Filosofía de la liberación. México: Edicol, 1977. . Filosofia da libertação na América Latina. São Paulo: Loyola, 1980. . Método para uma Filosofia da Libertação. São Paulo: Loyola, 1986. . 1492 - o encobrimento do Outro: a origem do mito da modernidade. Petrópolis: Vozes, 1993.

. Filosofia da libertação: crítica à ideologia da exclusão. São Paulo: Paulus, 1995.

Ética da libertação: na idade da globalização e da exclusão. Petrópolis: Vozes, 2000.

Alguns princípios para uma ética material de libertação. In: PIXLEY, J (Coord). Por um mundo diferente: alternativas para o mercado global. Petrópolis: Vozes, 2003. p. 23-35.

. 20 teses de política. São Paulo: Expressão popular, 2007a.

- Materialis para una política de la liberación. México: Universid Autónoma de Nuevo León, Plaza y Valdés Editores, 2007b.

. La cuestión ecológica en Marx. In: MARTíNEZ, L. M. (Ed.). Cultura y Naturaleza. Bogotá: Jardín Botánico de Bogotá, 2011.

- A produção teórica de Marx - um comentário aos Grundrisse. São Paulo: Expressão Popular, 2012. 


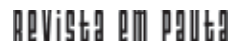

\} A ECOLOGIA POLÍTICA DE ENRIQUE DUSSEL - COSTA, C. A.; LOUREIRO, C. F. \}

DOI: $10.12957 /$ REP.2016.27859

FOSTER, J. B. A ecologia de Marx: materialismo e natureza. Rio de Janeiro: Civilização Brasileira, 2005.

HARVEY, D. O novo imperialismo. São Paulo: Edições Loyola, 2004.

LEHER, R. Hegemonia, contra-hegemonia e problemática socioambiental. In: FERRARO JR., L. A. (Org.). Encontros e caminhos: formação de educadoras(es) ambientais e coletivos educadores. Brasília: MMA/DEA, 2013.

. Educação ambiental como crítica ao desenvolvimento sustentável: desafios dos movimentos e das lutas sociais. In: LOUREIRO, C. F.; LAMOSA, R. (Org.). Educação ambiental no contexto escolar. Rio de Janeiro: Quartet/ CNPq, 2015.

LEHER, R. Iniciativa para a Integração da Infra-estrutura Regional da América Latina, Plano de Aceleração do Crescimento e a questão ambiental: desafios epistêmicos. In: LOUREIRO, C. F. B. (Org.). A Questão ambiental no pensamento crítico. Rio de Janeiro: Quartet, 2007. p. 223-255.

LOUREIRO, C. F. Sustentabilidade e educação: um olhar da ecologia política. São Paulo: Cortez, 2012.

LOUREIRO, C. F.; LAYRARGUES, P. Ecologia política, justiça e educação ambiental crítica: perspectivas de aliança contra-hegemônica. Trabalho, Educação e Saúde, Rio de Janeiro, v. 11, n. 1, jan./abr. 2013.

MONTAÑO, C.; DURIGUETO, M. L. Estado, classe e movimento social. São Paulo: Cortez, 2011.

PINTO, S.; RAPOSO, E. Política com paixão: a filosofia da libertação de Enrique Dussel. Revistas de Estudos e Pesquisas sobre as Américas, v. 2, n. 8, 2014.

PORTO-GONÇALVES, C. W. A ecologia política na América Latina: reapropriação social da natureza e reinvenção dos territórios. INTERthesis, Florianópolis, v. 9, n. 1, jan./jul. 2012.

. Os (des)caminhos do meio ambiente. São Paulo: Contexto, 2013.

. De envolvimento, meio ambiente e interesse público. Rio de Janeiro: [S.I], 2015a.

. Pela vida, pela dignidade e pelo território: um novo léxico teórico político desde as lutas sociais na América Latina/Abya Yala/Quilombola. Ciencias sociales: desafíos y perspectivas, n. 41, $2015 \mathrm{~b}$.

SILVA, J. V. M. Filosofia, responsabilidade e educação em Enrique Dussel. Perspectiva Filosófica, Recife, v. 2, n. 38, ago./dez. 2012.

VIEIRA, A. R. Marxismo e libertação: estudos sobre Ernst Boch e Enrique Dussel. São Leopoldo: Nova Harmonia, 2010.

. Filosofia da libertação e socialismo. In: VIEIRA, A. R. (Org.). Ética e filosofia crítica no século XXI. São Leopoldo: Nova Harmonia, 2010. 


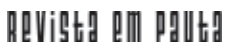

\} A ECOLOGIA POLITICA DE ENRIQUE DUSSEL - COSTA, C. A.; LOUREIRO, C. F. \}

DOI: $10.12957 /$ REP.2016.27859

ZANOTELLI, J. Educação e descolonialidades dos saberes, das práticas e dos poderes. Educação Pública, Cuiabá, v. 23, n. 53/2, maio/ago. 2014.

Recebido em 04 de maio de 2016.

Aprovado para publicação em 20 de dezembro de 2016.

DOI: $10.12957 /$ rep.2016.27859

\section{(c) (i)}

A Revista Em Pauta: Teoria Social e Realidade Contemporânea está licenciada com uma Licença Creative Commons Atribuição 4.0 Internacional. 